\title{
Plot test in a 50-year abandoned mine tailings dam
}

\author{
Lucas Garino Libardi ${ }^{1, *}$ and Luciano Agustín Oldecop ${ }^{1}$ \\ ${ }^{1}$ Instituto de Investigaciones Antisísmicas (IDIA), Universidad Nacional de San Juan, Av. Libertador Gral. San Martín oeste 1290, \\ San Juan, Argentina.
}

\begin{abstract}
Knowing the evolution of water content in a tailings dam is essential when analysing its stability. The case study is a small tailings dam abandoned more than 50 years ago, located in the Andes region of San Juan province, Argentina, where the climate is arid. This paper presents the results obtained in a plot test to study the interaction of tailings with the atmosphere, and to explain the reasons that generate internal zones in the dams with surprisingly high degrees of saturation, despite the strong water deficit of the site. The plot was hydraulically isolated on the four lateral faces where ten capacitive sensors were installed at different depths (volumetric moisture, matrix suction and temperature). At the beginning of the test, a major rainfall event was simulated with a sprinkler irrigation system. The plot was then allowed to interact freely with the atmosphere for an additional period of one and a half years. The records obtained suggest that the stratigraphy of the hydraulically deposited tailings has a preponderant influence on the interaction with the atmosphere. Heterogeneous flow phenomena and multiple capillary barriers during the infiltration and evaporation processes, respectively, appear to control the long-term moisture state of the tailings dam.
\end{abstract}

\section{Introduction}

Tailings dams are singular geotechnical structures. In contrast to most civil engineering works, tailings dams are designed to last indefinitely over time. This is a real challenge when it comes to assessing their structural safety. Until the middle of the 20th century, most of metalliferous mining consisted of small underground mines of high-grade ores, therefore with moderate waste generation. However, due to the growing demand for metals, the development of large earth-moving equipment and new extraction technologies, large deposits with exceptionally low grades are now economically viable. Thus, open-pit mines currently generate large amounts of waste, with mining tailings being one of the most important in terms of volume, exceeding all previous experiences in civil engineering fills of any kind.

Tailings dam failures have, in many cases, catastrophic consequences for the environment, for mine workers, and for nearby populations (Chandler and Tosatti 1995 [1], Harder and Stewart 1996 [2], Bligth 1997 [3], Fourie et al. 2001 [4], Alonso and Gens 2006 [5], Oldecop and Rodriguez 2006 [6], Bray and Frost 2010 [7], IEEIRP 2015 [8], Morgenstern et al. 2016 [9]).

Water management in tailings dams is a key factor for their safety (ICOLD 2001 [10], Davies 2002 [11], Bligth and Fourie 2005 [12], Rico et al. 2008 [13]). Historical cases of failures caused by very diverse factors and mechanisms (landslides, earthquakes, overtopping, piping and failure of auxiliary structures), show thatthe hydraulic operating conditions play a key role in the development of the failure, as well as in the magnitude of its consequences (Oldecop et al. 2008 [14]).
Recent analyses of failures indicate that, although the total number has decreased, the number of severe failures has increased over the past three decades and in most cases the instabilities are associated with abrupt changes in the hydraulic conditions of the tailings (Bowker and Chambers 2016 [15], Roche et al. 2017 [16]).

In recent years some cases of failure due liquefaction induced strength loss of tailings in a quasi-saturated state have been recorded in South America, producing loss of lives and severe damage to the environment (Verdugo et al. 2012 [17], Morgenstern et al. 2016 [10], Robertson et al. 2019 [18]).

Predicting the evolution of tailings moisture is fundamental to any analysis of tailings dam stability during operation as well as at the closure and abandonment stage. Such prediction is difficult to make, even more so in the long term, as it depends on a number of factors and complex phenomena involved in the interaction of tailings with the environment (atmosphere and foundation), such as infiltration, evaporation, capillary rise, transport and precipitation of salts, among others.

Since tailings are very fine-grained materials, the unsaturated phenomena play a significant role in the hydraulic and mechanical behaviour of the deposit (Zandarin et al. 2009 [19]).

In this context, an initiative was taken to study the longterm hydro-mechanical behavior of a small tailings dam of the Castaño Viejo mine that was abandoned about 50 years ago and since then has been interacting freely with the atmosphere.

\footnotetext{
* Corresponding author: 1garino@unsj.edu.ar
} 


\section{Methods}

\subsection{Case study: Castaño Viejo mine}

The "Castaño Viejo" mine is located $200 \mathrm{~km}$ from the city of San Juan, Argentina, in the Andes Mountains, near the right margin of the Castaño River. This area was exploited from 1956 to 1964 by National Lead Co S.A., obtaining a total of $46,640 \mathrm{t}$ of concentrates with $73-78 \%$ of $\mathrm{Pb}$, $75,588 \mathrm{t}$ with $50-60 \%$ of $\mathrm{Zn}$ and $8,000 \mathrm{t}$ with $14-21 \%$ of $\mathrm{Cu}$ (Gramage 1983 [20])

The tailings, composed of fine particles and water in a proportion of 60 to $70 \%$ in weight, were transported by gravity through channels and pipes to various storage sites (Ramírez et al. 2022 [21]). These small deposits, not exceeding $15 \mathrm{~m}$ in height, were built by hydraulic fill and are distributed between 2340 and 1935 meters above sea level.

The geotechnical field investigation was focused on the CV1 tailings dam, which is the largest. The field tests included manual boreholes, standard penetration tests, permeability and density tests, recovery of undisturbed samples, seismic and electrical tomography. In addition to the field tests, laboratory tests were carried out to physically characterize the tailings.

Due to the method of construction, the tailings present a spatially varying distribution of sizes, with the largest particles (fine sands) located near the points of discharge and the smallest sizes (silts and clays) reaching the sites furthest away in correspondence with the decant pond. In depth, very thin layers of tailings are formed by the superposition of discharges from different points (Figure 1).

Figure 2 shows the simplified stratigraphic profiles of the manual boreholes. An analysis of the recovered material shows that, except for a surface layer between 1 and 1.5 meters thick, the tailings have a surprisingly high moisture content. An estimate of the saturation degree (Figure 3), from the moisture and unit weight measured in the pits, gives values between 80 and 100\% (Garino et al. 2017 [22]).

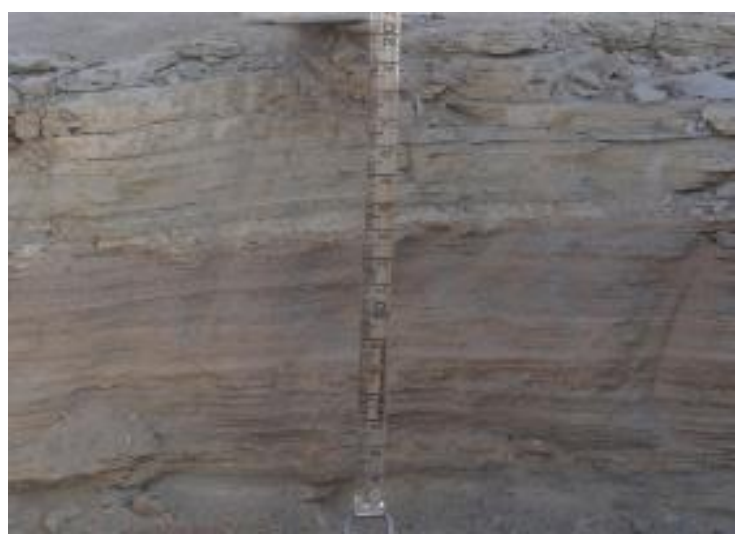

Fig. 1. Trial pit in CV1 tailings dam. Sequence of thin layers of silt and fine sand (first $0.20 \mathrm{~m}$ of depth).

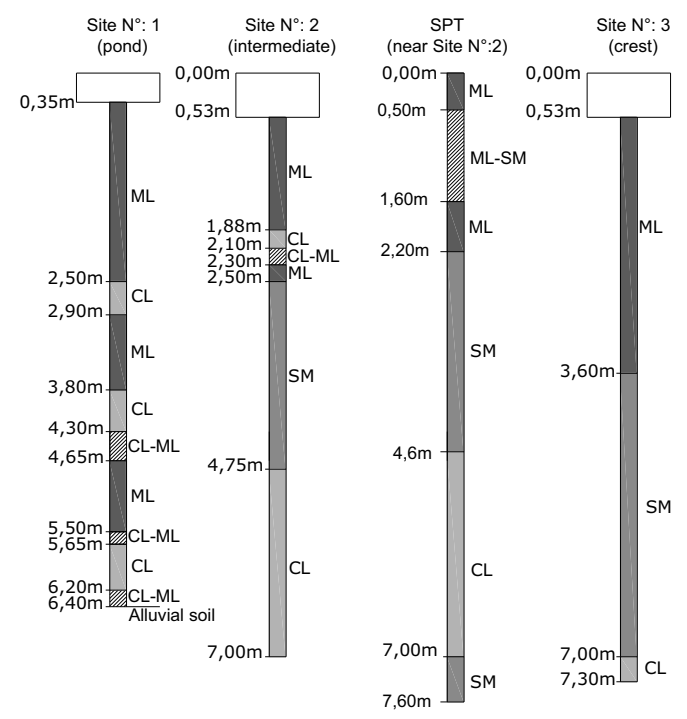

Fig. 2. Simplified stratigraphic profiles for samples recovered from boreholes in CV1 tailings dam.

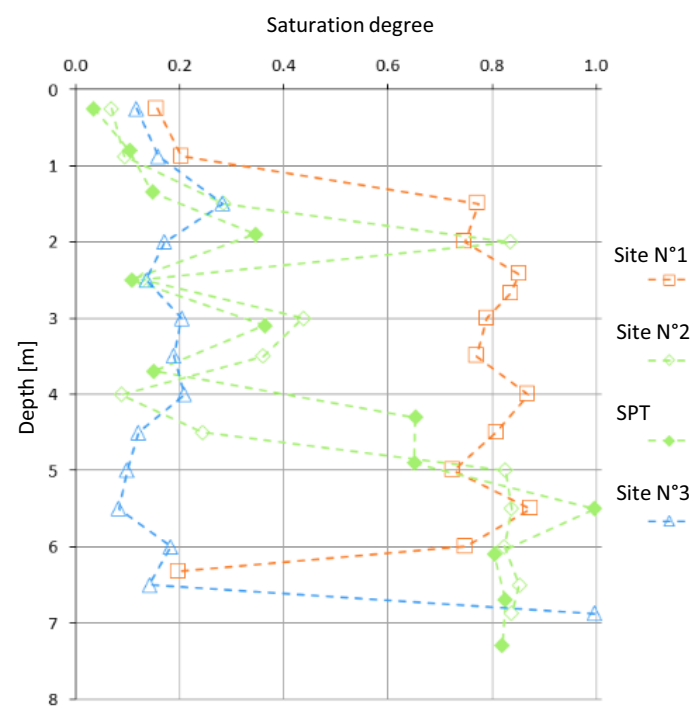

Fig. 3. Saturation degree for samples recovered from boreholes in CV1 tailings dam.

This finding is significant, considering that these tailings have been interacting freely with the atmosphere for more than 50 years in an arid climate that shows water deficit every month of the year, with an annual average deficit exceeding $1000 \mathrm{~mm}$.

\subsection{Experimental investigation - Plot tests}

The observation of high saturation degrees inside the tailings led to the execution a long-term field experiment (plot test) to investigate the evolution of water content in the surface layer of tailings dam CV1 which is in an unsaturated condition.

The CV1 tailings dam plot test lasted 527 days, from 1023-2012 to 3-3-2014.

Due to the time since the tailings discharge, no changes in porosity of the surface layer studied are expected to occur during the test. 


\subsubsection{Test preparation}

The tailings volume involved in the test has a surface area of 1 square meter and a depth of 0.80 meters. A trench was dug around this volume and the sides of the plot were hydraulically isolated by placing a polyethylene membrane. In the analysis of the sensor records ruled out the possibility of lateral water flow outside the studied volume.

Sensors were installed at different depths from the four plot side faces (Figure 4). Decagon 5TM and EC-5 sensors were used to measure volumetric water content. Decagon MPS-2 sensors were used for matric suction. Both type of sensors also measure the temperature. Figure 5 shows a simplified stratigraphic profile of the plot. The installation depth of the sensors is also indicated in the same figure.

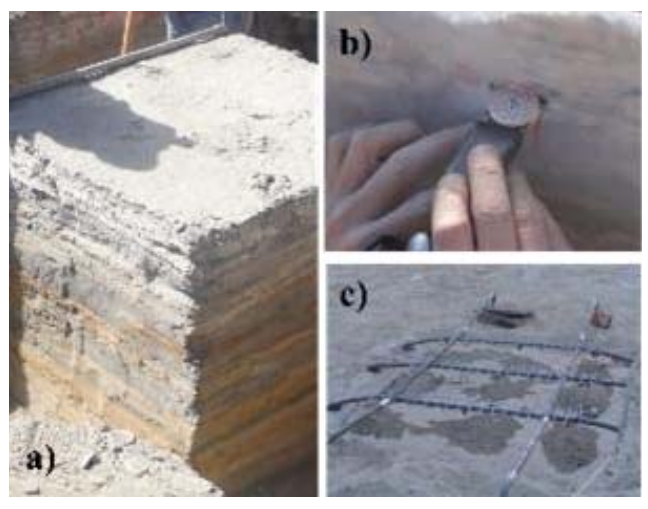

Fig. 4. a) Stratigraphy of the test plot. b) Sensor installation through the impermeable barrier. c) Irrigation system.

\subsubsection{Stages of the test}

The test was divided in two phases. Phase A, started on 10/23/2012 and lasted three days. Phase B immediately followed, lasting almost a year and a half (10/26/2012 through 04/04/2014).

During Phase A water was sprinkled over the plot, simulating rainfall. A volume of 125 litres was applied divided in 12 watering events, using a constant rate of 20 $\mathrm{mm} /$ hour. The duration and spacing of waterings was selected in such a way that no ponding or surface runoff was generated.

Simultaneously, the readings of the installed sensors began to be recorded. The records of the volumetric water content were converted to gravimetric moisture values from unit weight and density of solids determinations made on samples taken from the soil pits.

During Phase B, the surface of the plot was allowed to freely interact with the atmosphere. A weather station was installed near the plot, where the temperature, relative humidity and rainfall were recorded throughout the test period.
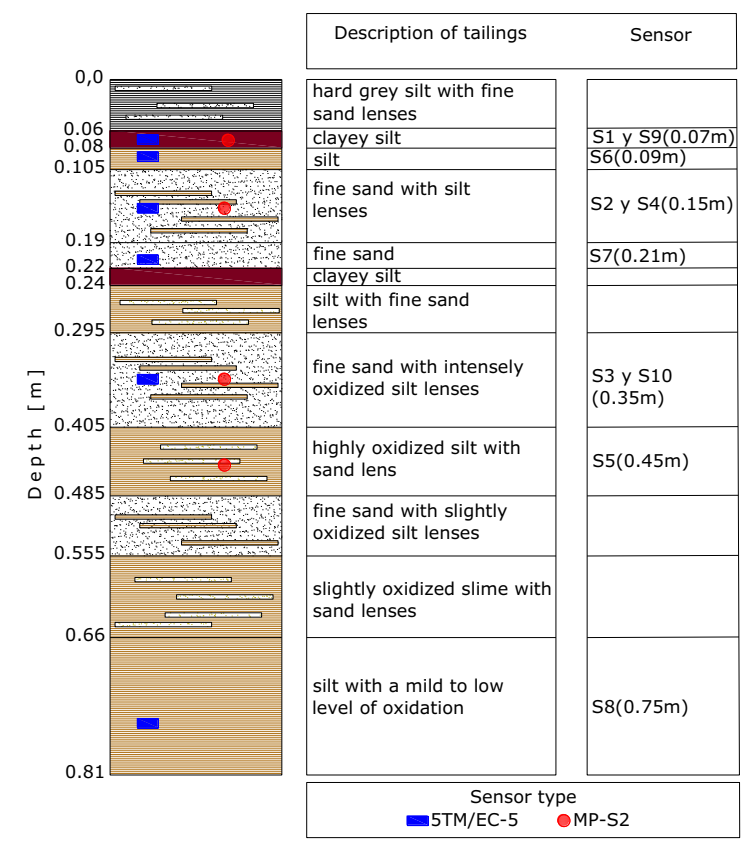

Fig. 5. Simplified stratigraphic profile and height location of the sensors.

\section{Plot test results}

\subsection{Evolution of soil moisture}

In Figure 6, the variation of water content obtained from the sensor readings during Phase $\mathrm{A}$ is shown together with the amount of water applied in the 12 watering events (Figure 6). The volume of water supplied is equivalent to a rainfall of $125 \mathrm{~mm}$ in 3 days. Regarding its magnitude, this would be a totally unlikely event at the study site, considering the historical meteorological records.

The first sensors to react are the surface sensors ( $\mathrm{S} 1$ and S6), although they do so with a delay of 14 hours with respect to the start of irrigation.

Sensor S6, located at a depth of $0.09 \mathrm{~m}$, reacted before sensor S1 located at a depth of $0.07 \mathrm{~m}$. This may be related to shrinkage cracking of the surface layer, forming preferential flow paths, which are not evident until the material is excavated. However, from 46 hours onwards the behaviour of both sensors, S1 and S6, became quite similar.

The deeper sensors (S2, S3, S7 and S8), did not react at all (WC $<2 \%$ ) during the first 18 hours (waterings 1 through 8).Surprisingly, the next sensor to react was the $\mathrm{S} 8$, located at $0.75 \mathrm{~m}$ deep. It seems even replicate the behaviour of sensor S6, which is much more shallow. However, after the 32-hour lapse between waterings 8 and 9, the sensor S8 did not react again to any subsequent infiltration event, while sensor S6 continued to do so.

Sensors S2, S3 and S7, located at a depth of 0.15, 0.35 and $0.21 \mathrm{~m}$ respectively, only reacted two and a half days after the start of the test, coinciding with the last two waterings (11 and 12).

It is interesting to note that the order and intensity of the reaction of the sensors seems to depend more on the type 
of material in which they are inserted, than on the depth of installation. The three sensors installed in silt layers (S1, S6 and S8) reacted earlier and more strongly than the three sensors installed in sands (S2, S3 and S7).

Figure 7 displays the records of water content along the first seven months of the test, the fluctuation in measurements caused by temperature variations is evident, affecting the surface sensors more than the deep ones. This behaviour is an artifact of the type of sensor used (Dorigo et al. 2013 [23], Kapilaratne and Lu 2017 [24]), which has not been attempted to correct in this work.

By the end of Phase A, sensors S1, S6 and S8 (in silts), began to register a sustained decrease in moisture, reaching values between 15 and $25 \%$, after one month. In contrast, the sensors in sand S2, S3 and S7 (in sands) slowly increased their readings until day 15 for S7, until day 30 for $\mathrm{S} 2$ and until day 60 for S3.

After 60 days without new inputs of water, all the sensors, except S7, stabilized at relatively low moisture values, between 3 and $6 \%$, although higher than the moisture initially measured. On the contrary, sensor S7 stabilized at a reading close to $20 \%$.

Figure 8 shows the moisture records for the entire test duration. The first (natural) heavy rains occurred from January to February 2013. The shallow sensors (S1 and S6), which at that time showed moisture levels below 5\%, were the first to react, followed by sensor S7 and S2. Finally, sensor S3 reacted, with almost 10 days of delay with respect to the beginning of the rains. Moreover, its increase was very smooth. Sensor S8 does not show any alteration. Unlike irrigation in Phase A, rainfall caused the sensors to react in a temporal order consistent with an infiltration front.

By the end of May 2013 (test day no. 216) a new rain episode occurred, a typical autumn-winter event of much lower magnitude than the summer rains $(\mathrm{P}=11 \mathrm{~mm})$. It caused a fast reaction in the shallow sensors S1 and S6 and no effects at all in the rest.

The rainy season 2013-2014, having a comparable total accumulated precipitation of that of the previous year, was characterized by lower magnitude events, more sparsely distributed over a four months period (day 373 through 490). In all the events, the shallow sensors S1 and S6 continued to react quickly and with amplitudes roughly proportional to the magnitude of the rainfall that caused them. Sensor S7 also showed reaction to each rain event, although more delayed and smoothed than that of the shallow sensors. Furthermore, those reactions are overlaid to a drying trend between days 420 and 480 (midDecember to mid-February). This may be related to the combination of high summer temperatures and relatively low rainfall in the same period (compared to the first summer). However, from the February rains onwards, sensor S7 increased its readings again, while sensor S6 $(0.09 \mathrm{~m})$ reacted quickly and then showed a drying process once the rains ceased. Of the rest of the sensors, only the S8 remained operational in the second rainy season and had no discernible reaction

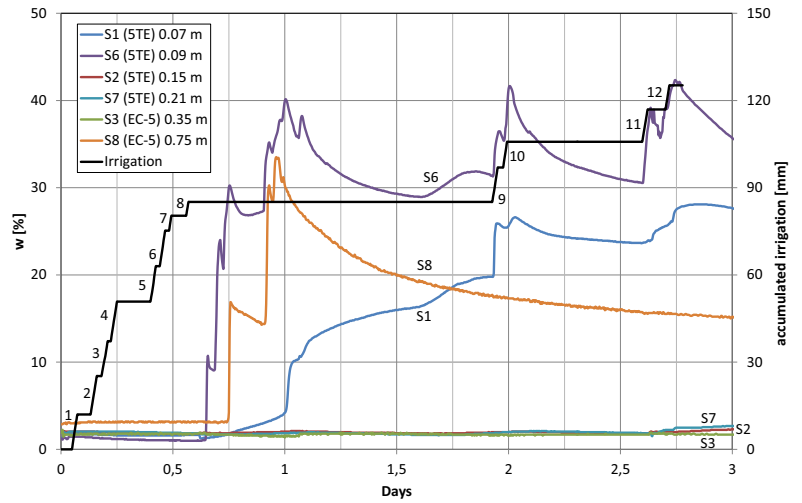

Fig. 6. Variation of water content during Phase A.

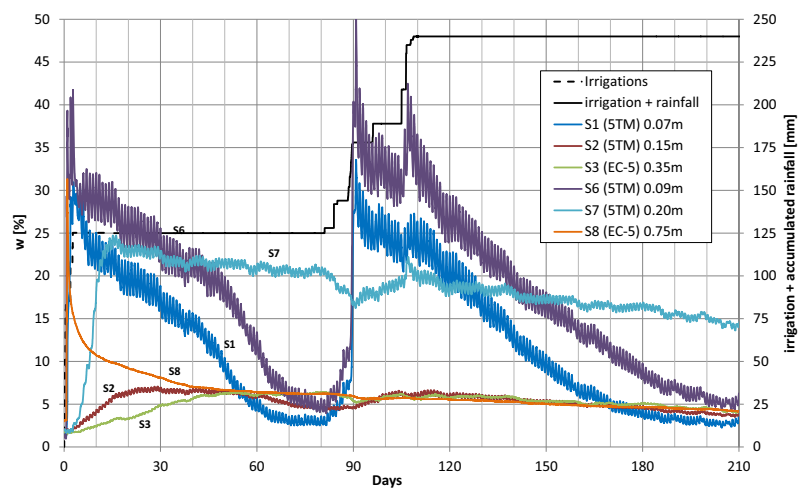

Fig. 7. Variation of water content during the first seven months of the experiment.

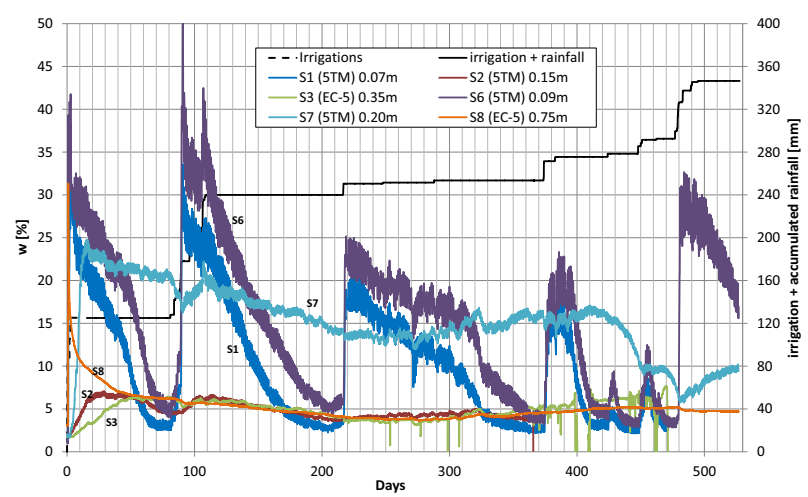

Fig. 8. Variation of water content during the whole test.

\subsection{Temperature variation}

The shallow sensors recorded temperatures above $40^{\circ} \mathrm{C}$ in summer (S1 and S6) and below-zero values during the winter. As expected, the range of recorded temperatures decreases with depth. For the deepest sensor (S8) the maximum temperature recorded is $25{ }^{\circ} \mathrm{C}$ while the minimum are around $10{ }^{\circ} \mathrm{C}$. Although the minimum temperatures at the intermediate sensors (S7 and S3) are not below zero, during the winter of 2014 , they reached very low values, 1 and $4{ }^{\circ} \mathrm{C}$ respectively (Figure 9). 


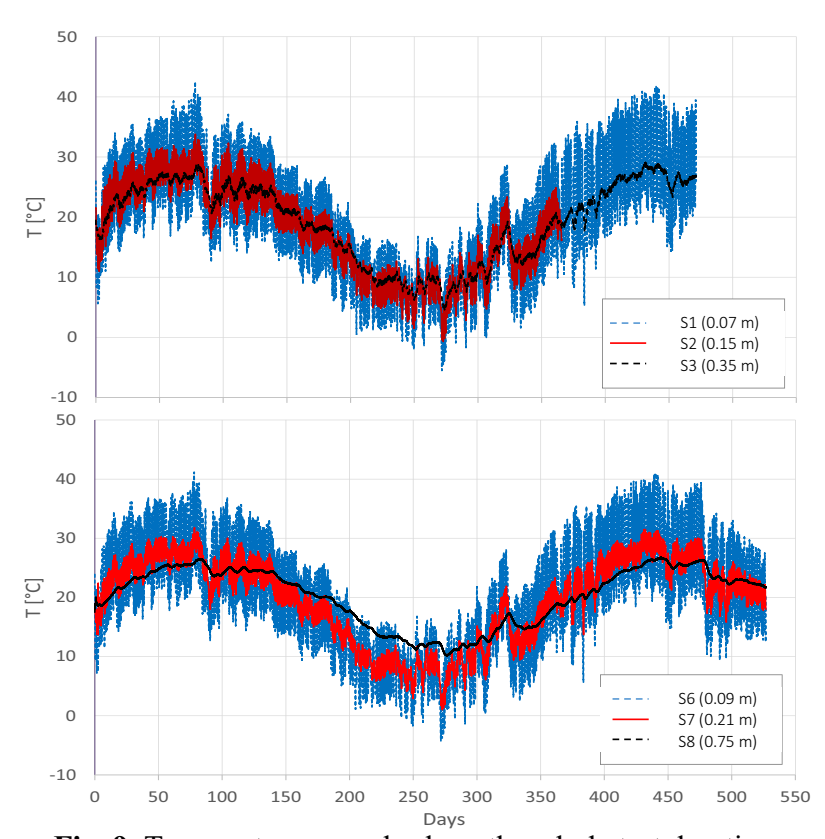

Fig. 9. Temperature records along the whole test duration.

\subsection{Matric suction measurements}

Due to a malfunction of the datalogger, suction measurements are only available for phase B of the test (Figure 10). The records of the suction sensors are difficult to interpret due to the strong dependence of the readings on the temperature, which causes large daily fluctuations.

Temperature can influence the dielectric properties of the soil in many ways (Malmberg and Maryott 1956 [25], Or and Wraith 1999 [26], Seyfried and Grant 2007 [27]). To try to overcome this problem, the data were corrected with the equation proposed by Walthert and Schleppi (2018) [28] for the MPS-2 sensor:

$$
\Delta p F=\left(6.206 \Delta T+0.1137 \Delta T^{2}\right) \times e^{-22.76 /(p F+1.25)}
$$

where: $\mathrm{pF}=\log$ (suction $[\mathrm{kPa}]$ ) and $\Delta \mathrm{T}\left[{ }^{\circ} \mathrm{C}\right]$ is the difference between the current and reference temperature. Equation 1 gives the corrected suction values at $22^{\circ} \mathrm{C}$ reference temperature (temperature used for factory calibration) depending on the measured temperature and suction. In the correction process, it is necessary to reject readings exceeding the sensor range (measured suction $>$ $100 \mathrm{MPa}$ ) or when temperatures were outside the range used for fitting equation (1) $\left(4\right.$ to $\left.26^{\circ} \mathrm{C}\right)$.

Figure 10 shows the corrected suction readings. The data should be interpreted with caution since the corrections applied range from $-95 \%$ to $+70 \%$ from the measured values.

Analyzing the suction records, the shallowest sensor, S9 $(0.09 \mathrm{~m})$, reacts with a sudden drop in suction at every rain event. In the sensor S4 $(0.15 \mathrm{~m})$, suction also falls following the most intense rain events, although with much smaller amplitude than the response of S9 sensor. Sensor S10 $(0.35 \mathrm{~m})$ does not show any correlation with rain events or with the rest of the sensors. Sensor S5 $(0.45$ $\mathrm{m})$ shows a moderate tendency to dry out throughout the test, but apparently without any influence from the weather. A remarkable aspect is that, in general, the suction measured by sensor $\mathrm{S} 10(0.35 \mathrm{~m})$ is always higher than that measured by sensor S4 $(0.15 \mathrm{~m})$ throughout the experiment.

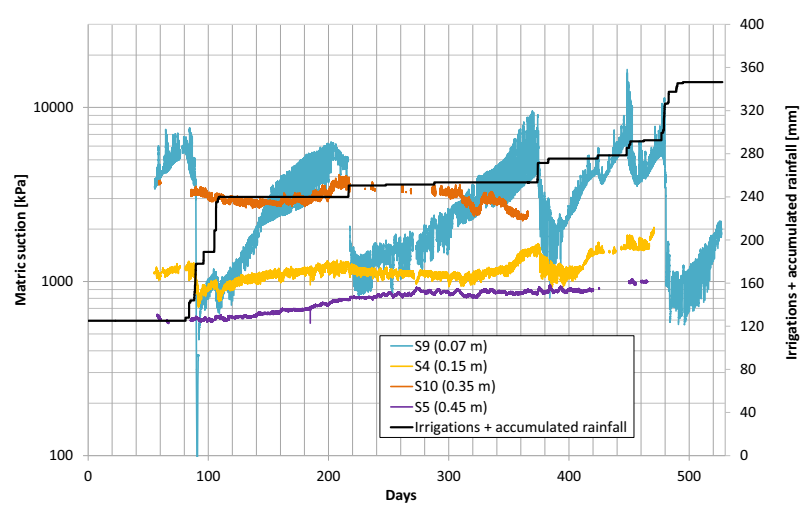

Fig. 10. Temperature-corrected suction records along the whole test duration. Accumulated irrigation + rainfall is also shown for reference.

\section{Discussion}

\subsection{Infiltration}

The irrigation test in Phase A and each rainy season in Phase B of the experiment, implied the input of comparable quantities of water, 125, 120 and $105 \mathrm{~mm}$ respectively. The important difference is that in the irrigation test water was applied in only 3 days, while the rainy seasons lasted 30 days in the 2012-2013 and more than 3 months in 2013-2014.

In addition to summer rains, some autumn-winter rains were recorded in 2013, typically of lesser magnitude and intensity than summer rains. However, these minor events are also reflected in the three shallowest sensors: $\mathrm{S} 1(0.07$ $\mathrm{m})$, S6 (0.09 m) and S9 (0.07m), (Fig. 8 and Fig. 10). Evidently, the surface layer, with a thickness of only 0.10 $\mathrm{m}$, is strongly influenced by the atmospheric agents, despite its hard consistency and low permeability. It is possible that the pattern of small cracks observed in this layer has a determining influence on the infiltration. It has been observed in laboratory experiences that the networks of preferential pathways created by the cracks and interfaces between the thin layers can generate variations of permeability of more than an order of magnitude if the same homogeneous tailings package is taken as a reference (Rodríguez 2002 [29], Rodríguez and Oldecop 2006 [30]).

As previously noted, during Phase A of the test the response of the sensors installed at greater depth does not reflect a wetting front moving downwards. The order of response seems more influenced with the type of material in which the sensor was installed. For example, sensors $\mathrm{S} 1(0.07 \mathrm{~m})$, S6 $(0.09 \mathrm{~m})$ and S8 $(0.75 \mathrm{~m})$, installed in layers of silt and clayey silt, react two days earlier than the rest of sensors S2 $(0.15 \mathrm{~m}), \mathrm{S} 7(0.20 \mathrm{~m})$ and S3 $(0.35$ $\mathrm{m})$, installed in sand layers. Moreover, within each of these groups, some anomalous behaviors are observed. 
For example, sensor S6 reacts earlier and much more abruptly than sensor S1, even though the first is deeper. In the group of sensors installed in sand, sensor S7 reaches significantly higher water content values than sensor $\mathrm{S} 2$, even though the later was installed $0.05 \mathrm{~m}$ above the former.

These anomalies can be explained by the occurrence of heterogeneous flow during the infiltration process. Heterogeneous flow may be associated with cracks and fissures due to drying shrinkage. However, such features were only observed in the surface layer, down to a depth of only $0.07 \mathrm{~m}$. It is more likely that the heterogeneous flow is due to the instability of the wetting front, a phenomenon also known as "fingering". Fingering can occur in homogeneous materials subjected to high infiltration rates or it can also develop in materials where layers of quite different grain size alternate, as in the case studied. Each interface between an upper layer of fine material (silt or clay) and a lower layer of coarse material (sand) conforms a capillary barrier. In order for the wetting front to pass through such a barrier, the degree of saturation in the fines layer must rise so that suction falls and the water entry value of the coarser material is reached (Stormont and Morris 1998 [31]).

In this condition any heterogeneity can produce local rupture of the capillary barrier and initiate a concentrated flow through the coarse layer.

Such heterogeneous flow may explain why the deepest sensor (S8) reacts earlier than the intermediate-depth sensors, installed in sand. A surprising aspect of the behavior of this sensor S8 is that after its rapid reaction to waterings 1 through 8 , the readings showed a sustained decay throughout the rest of the experiment. If the mechanism by which the water reached the depth of this sensor was "fingering", then it implies that from the second day on, this phenomenon was suppressed.

One possible explanation is that the high irrigation rate applied on the first day of the experiment, induced "fingering" and that the intensity of the rest of waterings and rainfalls that followed, was not sufficient to provoke the phenomenon again. A different explanation could be that the remaining moisture of the first irrigations made the capillary barrier effect more effective in the multiple interfaces contained in the package.

All other sensors, except S8, have some kind of response to rain events, being less evident and with a longer delay in the intermediate depth sensors (S2, S3 and S7), than in the surface sensors ( 1 1 and S6).

\subsection{Evaporation}

During the periods of the test without irrigation or rain, a gradual decrease in the VWC sensors readings was observed (Figs. 7, Fig. 8 and Fig. 10). However, also in this situation, two groups of sensors with different behaviour can be distinguished.

The shallow sensors, S1 (0.07 m), S6 (0.09 m), S2 (0.15 $\mathrm{m})$ and $\mathrm{S} 7(0.20 \mathrm{~m})$, have the typical behaviour of a capillary rise and evaporation process. The suction sensors S9 $(0.07 \mathrm{~m})$ and S4 $(0.15 \mathrm{~m})$ are also consistent with such a process.
On the other hand, the readings of sensor S3 $(0.35 \mathrm{~m})$, fluctuated most of the time around a moisture value close to $6 \%$, with much attenuated reactions to periods of infiltration or drying (Fig 10). Sensor S8 (0.75 m) does not show significant variations or reactions after the end of Phase A.

It is difficult to believe that in such an arid environment, where potential evaporation is 10 times greater than annual rainfall, the atmosphere cannot extract moisture from layers located only $0.35 \mathrm{~m}$ deep.

However, the water content records suggest that the layers located below that depth are not affected by evaporation, at least permanently. Rather, it seems that the variations of moisture respond to a redistribution of water or percolation to deeper layers.

Matric suction records seem to confirm this hypothesis. Sensor S10 $(0.35 \mathrm{~m})$ records a suction always greater than sensor S4 $(0.15 \mathrm{~m})$, a situation which makes capillary rise impossible.

Figure 11 presents the matric suction measurements vs. saturation degree (the latter calculated from the volumetric moisture measurements), for pairs of sensors installed at the same depth.

Data from the retention curve of silty sand (SM) and clayey silt (ML-CL), obtained in the laboratory with samples of "Castaño Viejo", are included in the same figure. Curves were fitted to the laboratory data using the expression proposed by Van Genuchten (1980) [32].

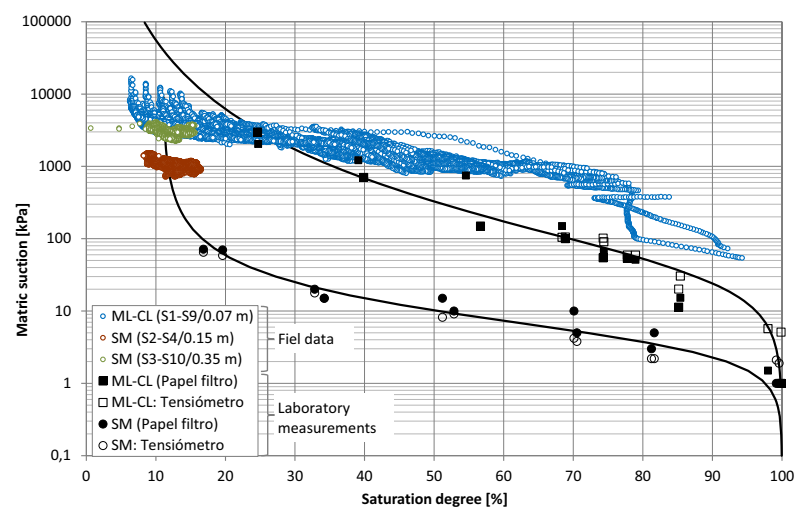

Fig. 11. Field data of matric suction vs. degree of saturation (from VWC measurements), compared to laboratory retention curve data for similar materials of the instrumented layer. Continuous lines are Van Genuchten curves fitted to the laboratory data.

Considering the uncertainties affecting the field matric suction measurements and that the suction and moisture sensors did not measure in the same point, but were installed at a horizontal distance of approximately $0.50 \mathrm{~m}$, the correlation between field and laboratory data is reasonably good.

Figure 11 shows how, while the superficial layer of silt interacts with the atmosphere, covering practically the whole range of its retention curve, the layers of sand at 0.15 and $0.35 \mathrm{~m}$ depth are maintained throughout the test in the residual saturation zone. In that area of the retention curve it can be assumed that the liquid phase has no continuity, impeding liquid flow. 
Also, in this case, the mechanism that allows explaining this behavior is the capillary barrier. In a package of alternating layers of fine (silt) and coarse (sand) materials, the hydraulic balance determines that suction of two juxtaposed layers must be equal at the interface. Otherwise, because their retention curves are radically different, the distribution of water content varies sharply at the interface: silts have high moisture while sands have low moisture. This effect has already been observed when determining the water content of samples at different depths obtained from manual boreholes.

In such a system, having a certain amount of water entered, for example from rainfall, the layers of silt would absorb moisture, drying out the layers of sand. This would cause the unsaturated permeability of the sand to drop drastically, reaching a state where the liquid phase loses continuity.

In this way, sand layers would become barriers to capillary rise and then the only possible transport of water to the atmosphere would be by molecular vapor diffusion. But in addition, the layers of silt, having high degrees of saturation, would constitute a barrier to the flow of gases, including vapor diffusion. At this point, drying would be impeded, leaving the lower layers completely isolated from the atmospheric agents.

\section{Conclusions}

The tailings studied have a stratigraphic profile composed of very thin layers, where grain size alternate between silt (ML), clay (CL) and fine sand (SM). The structure overall is not very dense, and this is due to the sedimentation of the particles in the presence of water. However, on the surface a hard layer or crust formed by silts with thin sandy layers is developed. The characteristics described are consistent with the constructive methodology (hydraulic fill) used in the Castaño Viejo tailings dams, an ancient technique, but widely used today.

For typical rain events in the area (even for those of extraordinary intensity that occurred in January 2013), the infiltration penetrates a limited depth, probably a little more than $0.35 \mathrm{~m}$ and less than $0.75 \mathrm{~m}$. Only for the artificially high intensity of the irrigation experiment (phase A of the trial), penetration of the infiltration was observed to reach $0.75 \mathrm{~m}$ or more, although the latter could also occur in the case of rains of lesser intensity but that generate ponding.

The experiment shows signs of fingering during the infiltration processes, both in the irrigation of phase A and in the rains of phase $B$. The development of the phenomenon seems to increase with the intensity of the rain and therefore also the depth of water penetration is greater for more intense rains. In contrast, when the fingering phenomenon does not develop, the depth of penetration of the infiltration is limited by the capillary barrier effect between the tailings layers.

In the evaporation stages, the experiment suggests that the drying effects do not extend beyond a depth of 0.20 to $0.35 \mathrm{~m}$.

The alternation of thin layers of tailings of different sizes (comparable to sand and silt particles), forms a barrier system that is extraordinarily effective in preventing water evaporation, both by capillary rise and vapor diffusion.

It can be concluded that, in the case studied, the active layer, where the processes of water exchange with the atmosphere take place, has a depth between $0.35 \mathrm{~m}$ and $0.75 \mathrm{~m}$.

The observation of the records gives indications that the water balance for the plot is positive, given an asymmetric behavior of the system, where the penetration of the infiltration processes is deeper than the extension of the effects of drying by evaporation, at least during the period studied.

If this situation could be extrapolated to a longer period, it would imply that in the long term the deposit would have a net water input, which after reaching the deep layers could no longer be extracted by the atmosphere.

This conclusion could explain the large amount of water that has been found stored in these types of deposits, even though very long periods of time have passed since they were abandoned.

\section{References}

1. R. J. Chandler and G. Tosatti (1995). The Stava dams failure, Italy, July, 1985. Proceedings of the Institution of Civil Engineers, 113, 67-79.

2. L. F. Harder and J.P. Stewart (1996). Failure of Tapo Canyon Tailings Dam. J. Perform. Constr. Facil. ASCE, 10: 3, 109-114.

3. G. E. Bligth (1997). Destructive mudflows as a consequence of tailing dyke failures. Proceedings of the Institution of Civil Engineers, 125, 9-18.

4. A. B. Fourie, G. E. Blight, G. Papageorgiou (2001). Static liquefaction as a possible explanation for the Merriespruit tailings dam failure. Can. Geotech. J. 38, 707-719.

5. E. E. Alonso and A. Gens (2006). Aznalcóllar dam failure. Part 1: Field observations and material properties. Géotechnique, 56: 3, 165-183.

6. L. Oldecop y R. Rodríguez (2006). Estabilidad y seguridad de depósitos de residuos mineros. Los residuos minero-metalúrgicos en el medio ambiente. Editorial Instituto Geológico y Minero de España, 197-244.

7. J. D. Bray and J. D. Frost (2010). Geo-Engineering Reconnaissance of the 2010 Maule, Chile Earthquake, a report of the NSF-sponsored GEER Association Team. http://www.geerassociation.org/.

8. IEEIRP (2015) Report on Mount Polley Tailings Storage Facility Breach. Independent Expert Engineering Investigation and Review Panel. January 30, 2015.

9. N. R. Morgenstern, S. G. Vick, C. B. Viotti, B. D. Watts (2016). Fundão Tailings Dam Review Panel. Report on the Immediate Causes of the Failure of the Fundão Dam.

10. ICOLD (2001) Tailings dams risk of dangerous occurrences, lessons learnt from practical 
experiences. Bulletin 121, United Nations Environmental Programme (UNEP) Division of Technology, Industry and Economics (DTIE) and International Commission on Large Dams (ICOLD), Paris, 2001.

11. M. P. Davies (2002). Tailings Impoundment Failures: Are Geotechnical Engineers Listening? Geotech. News, 20, 31-36.

12. G. E. Bligth and A. B. Fourie (2005). Catastrophe revisited - disastrous flow failures of mine and municipal solid waste. Geotech. Geol. Eng. 23, 219248.

13. M. Rico, G. Benito, A. R. Salgueiro, A. DíezHerrero, H. G. (2008). Reported tailings dam failures - A review of the European incidents in the worldwide context. J. Hazard. Mater. 152, 846-852.

14. L. Oldecop, F. Zabala, R. Rodríguez, L. Garino (2008). Funcionamiento hidráulico, estabilidad y mecanismos de rotura de presas de relaves mineros. Proceeding of $V$ Congreso Argentino de Presas y Aprovechamientos Hidroeléctricos. Tucumán, Argentina.

15. L. N. Bowker and D. M. Chambers (2015). The Risk, Public Liability, and Economics of Tailings Storage Facility Failures. Earthwork Act, 1-56.

16. C. Roche, K. Thygesen, E. Baker (2017). Mine Tailings Storage: Safety Is No Accident. A UNEP Rapid Response Assessment. United Nations Environment Programme and GRID-Arendal, Nairobi and Arendal, www.grida.no.

17. R. Verdugo, N. Sitar, J. D. Frost, J. D. Bray, G. Candia, T. Eldridge, Y. Hashash, S. M. Olson, A. Urzua (2012). Seismic Performance of Earth Structures during the February 2010 Maule, Chile, Earthquake: Dams, Levees, Tailings Dams, and Retaining Walls. Earthq. Spectra 28, 75-96.

18. P. K. Robertson, L. de Melo, D. J. Williams, G. Ward Wilson (2019). Report of the expert panel on the technical causes of the failure of Feijão Dam I. 12 December, 2019.

19. M. T. Zandarín, L. Oldecop, R. Rodríguez, F. Zabala (2009). The role of capillary water in the stability of tailing dams. Eng Geol. 105: 1-2, 108-118.

20. R. Gramage (1983). Estudio geológico minero de las vetas Compañía y Flor de Castaño, Distrito Minero Castaño Viejo, Pcia. de San Juan. Trabajo Final de la Carrera Licenciatura en Ciencias Geológicas. Facultad de Ciencias Exactas, Físicas y Naturales. Universidad Nacional de San Juan, Argentina.

21. M. Ramírez, L. Salinas, H. Carrascosa, M. Negrelli (2002). Caracterización y evaluación de las presas mineras del Distrito Castaño Viejo, Calingasta, San Juan. Proceeding of II Congreso Argentino de Presas y Aprovechamientos Hidroeléctricos, San Juan, Argentina.

22. L. Garino, G. Rodari, L. Oldecop. (2017). Characterization of mine waste materials after 50 years of climate interaction. Proceeding of Second
Pan-American Conference on Unsaturated Soils, Dallas, United States.

23. W. A. Dorigo, A. Xaver, M. Vreugdenhil, A. Gruber, A. Hegyiová, A. D. Sanchis-Dufau, D. Zamojski, C. Cordes, W. Wagner, M. Drusch (2013). Global automated quality control of in situ soil moisture data from the International Soil Moisture Network. Vadose Zone J. 12: 3.

24. R. J. Kapilaratne and M. Lu (2017). Automated general temperature correction method for dielectric soil moisture sensors. J. Hydrol. 551, 203-2016.

25. C. Malmberg and A. Maryott (1956): Dielectric constant of water from $0^{\circ}$ to $100^{\circ} \mathrm{C}$. J. Res. Natl. Bur. Stand. 56, 1-8.

26. D. Or and J. M. Wraith (1999). Temperature effects on soil bulk dielectric permittivity measured by time domain reflectometry: A physical model. Water Resour. Res. 35, 371-383.

27. M. S. Seyfried and L. E. Grant (2007). Temperature effects on soil dielectric properties measured at 50 MHz. Vadose Zone J. 6, 759-765.

28. L. Walthert and P. Schleppi (2018). Equations to compensate for the temperature effect on readings from dielectric Decagon MPS-2 and MPS-6 water potential sensors in soils. J. Plant. Nutr. Soil Sci. 181, 749-759.

29. R. Rodríguez (2002). Estudio experimental de flujo y transporte de cromo, níquel y magnesio en residuos de la zona minera de Moa (Cuba): influencia del comportamiento hidromecánico. $\mathrm{PhD}$ Thesis, Universitat Politècnica de Catalunya, Barcelona.

30. R. Rodríguez y L. Oldecop (2006). Propiedades físicas, mecánicas e hidrogeológicas de los residuos minero-metalúrgicos sólidos. Los residuos minerometalúrgicos en el medio ambiente. Editorial Instituto Geológico y Minero de España., Madrid, 2006.

31. J. C. Stormont and C.E. Morris (1998). Method to estimate water storage capacity of capillary barriers. J. Geotech. Geoenviron. Eng. 124: 4, 297-302.

32. M. Th. Van Genuchten (1980). A closed-form equation for predicting the hydraulic conductivity of unsaturated soils. Soil Sci. Soc. Am. J. 44, 892-898. 